\title{
Palladium-Catalyzed Three-Component Coupling of
}

\section{1,1-Dibromoalkenes, Vinylzinc Chloride, and Soft}

\author{
Nucleophiles: One-Pot Synthesis of \\ 1,3-Disubstituted Allenes
}

\section{Eri Sawano ${ }^{\dagger, *}$ and Masamichi Ogasawara ${ }^{*, \dagger}$}

Department of Natural Science, Graduate School of Science and Technology and Research Cluster on "Innovative Chemical Sensing", Tokushima University, Tokushima 770-8506, Japan

Graduate School of Life Science, Hokkaido University, Kita-ku, Sapporo 001-0021, Japan

\section{Supporting Information}

\section{Table of Contents}

${ }^{1} \mathrm{H}-,{ }^{13} \mathrm{C}\left\{{ }^{1} \mathrm{H}\right\}-$, and ${ }^{19} \mathrm{~F}-\mathrm{NMR}$ Spectra of Allenic Products $5 \ldots \ldots \ldots \ldots \ldots$ S2-S28 


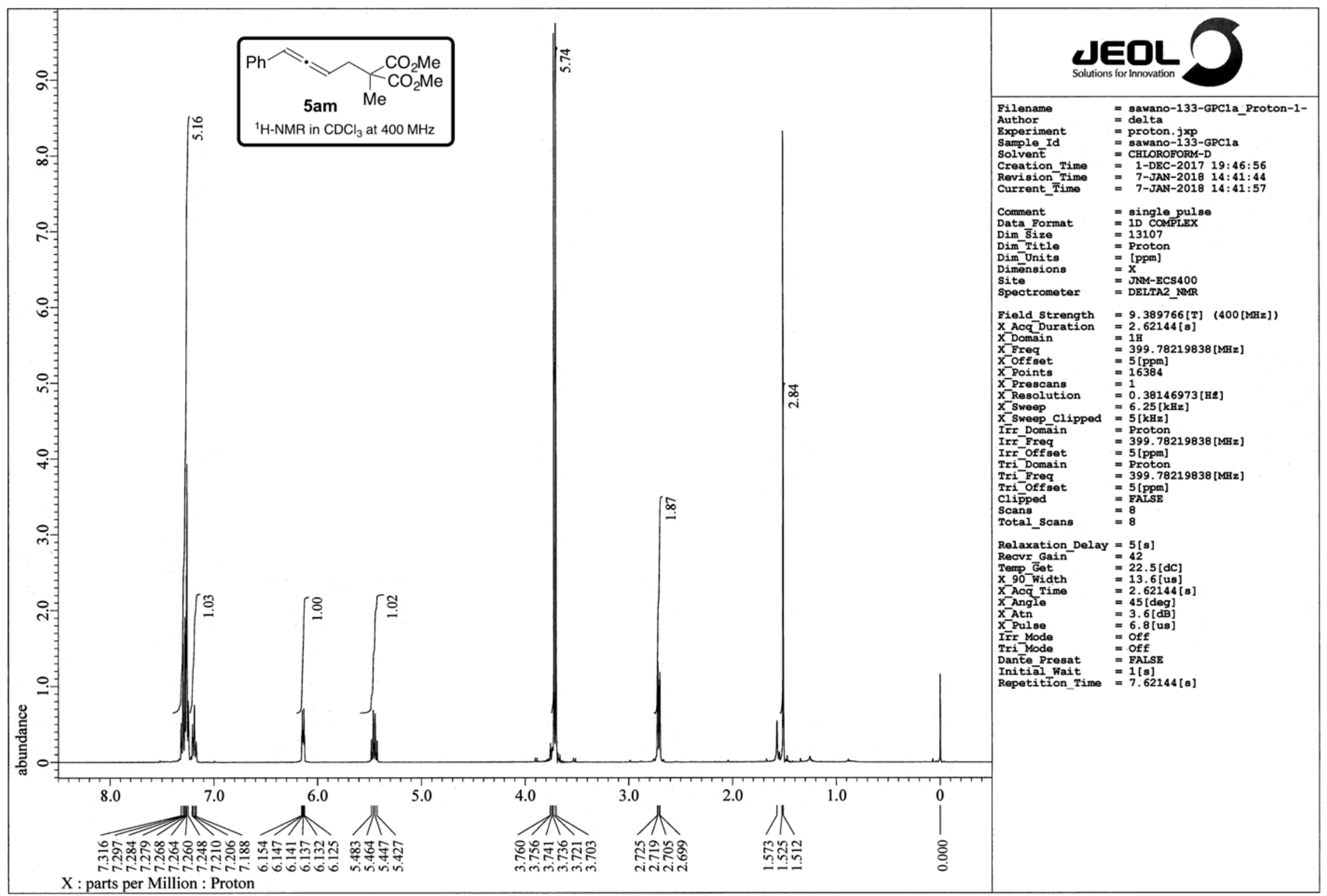

Figure S1. ${ }^{1} \mathrm{H}-\mathrm{NMR}$ Spectrum of $\mathbf{5 a m}$ in $\mathrm{CDCl}_{3}$ at $400 \mathrm{MHz}$. 


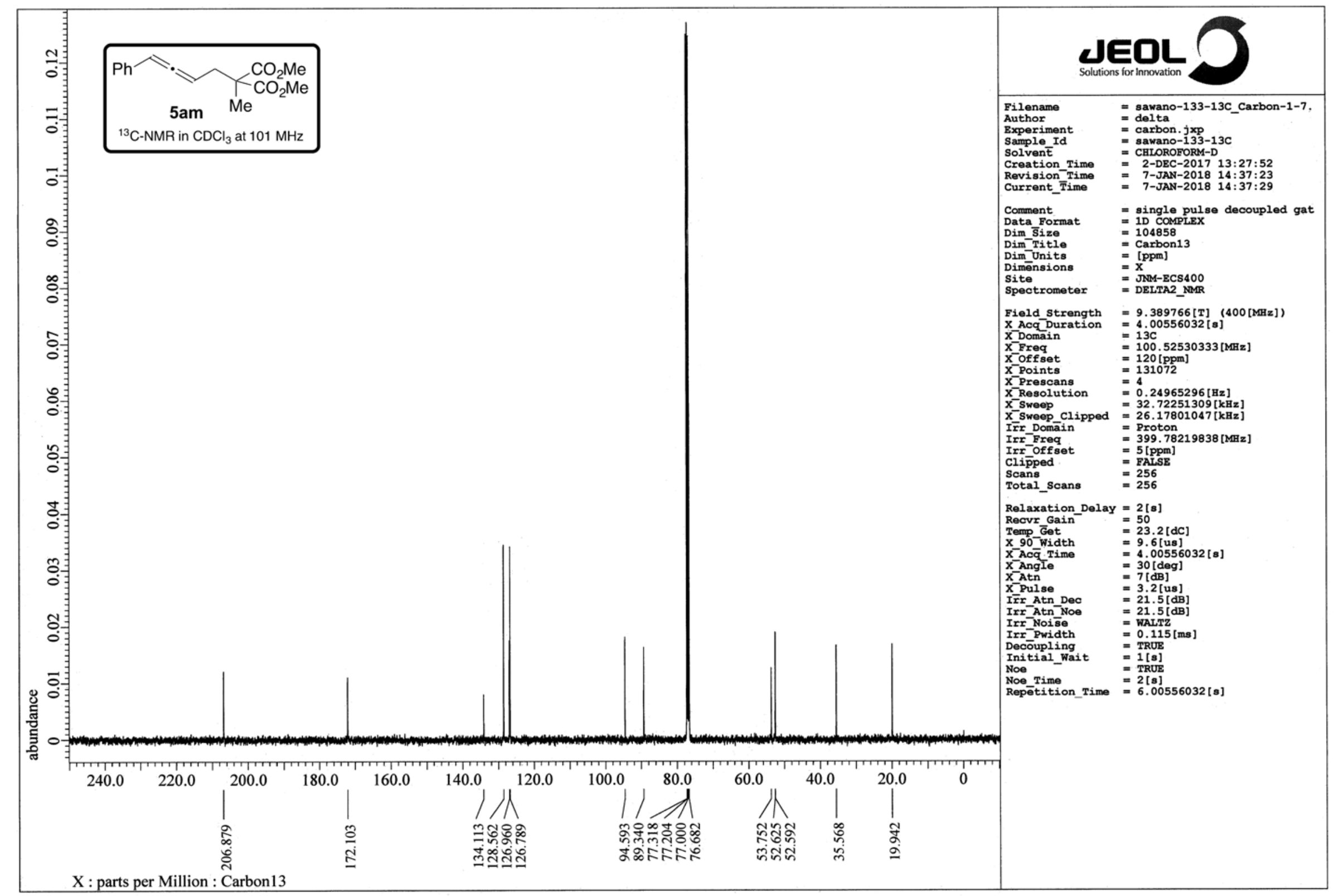

Figure S2. ${ }^{13} \mathrm{C}-\mathrm{NMR}$ Spectrum of $\mathbf{5 a m}$ in $\mathrm{CDCl}_{3}$ at $101 \mathrm{MHz}$. 


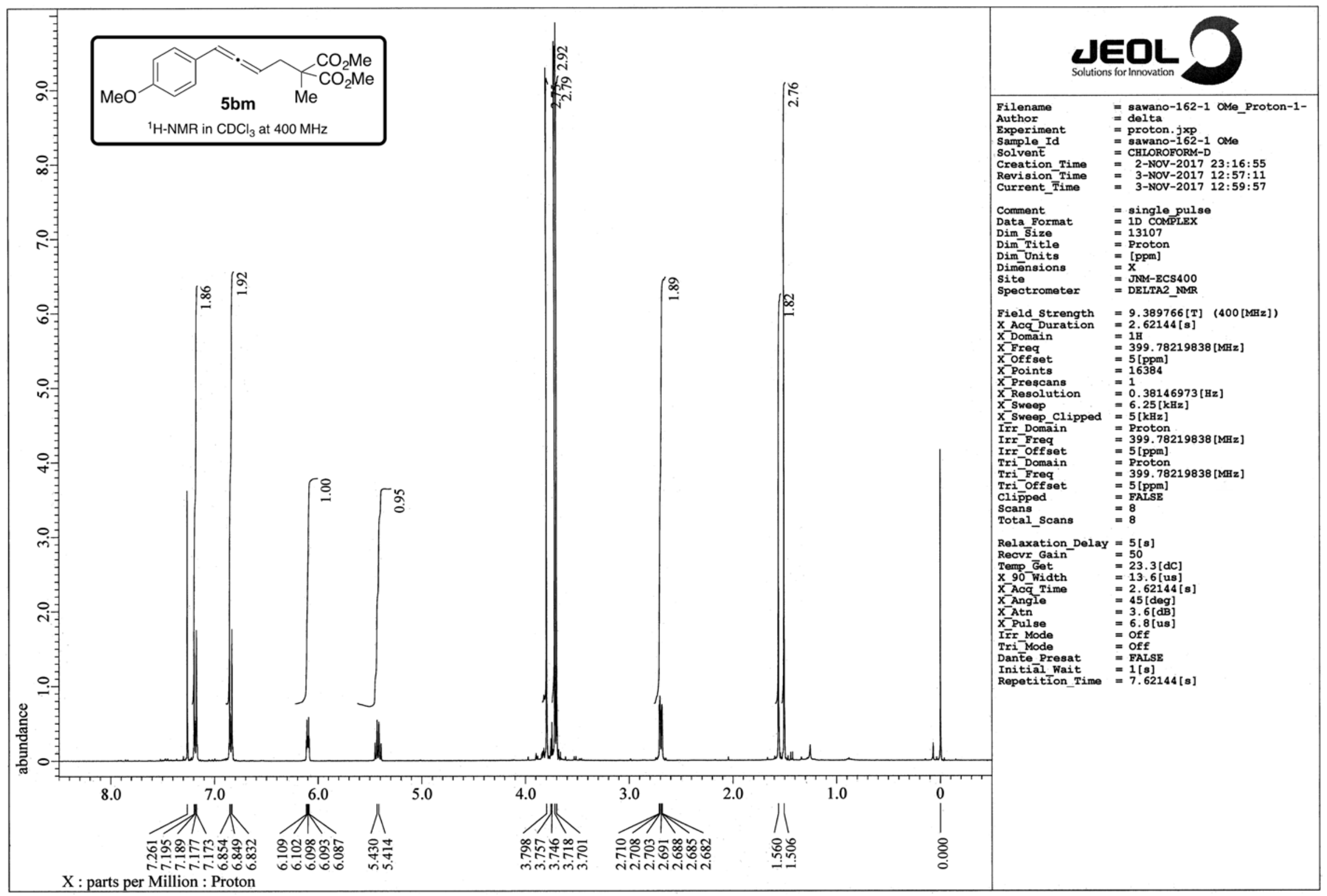

Figure S3. ${ }^{1} \mathrm{H}-\mathrm{NMR}$ Spectrum of $\mathbf{5 b m}$ in $\mathrm{CDCl}_{3}$ at $400 \mathrm{MHz}$. 


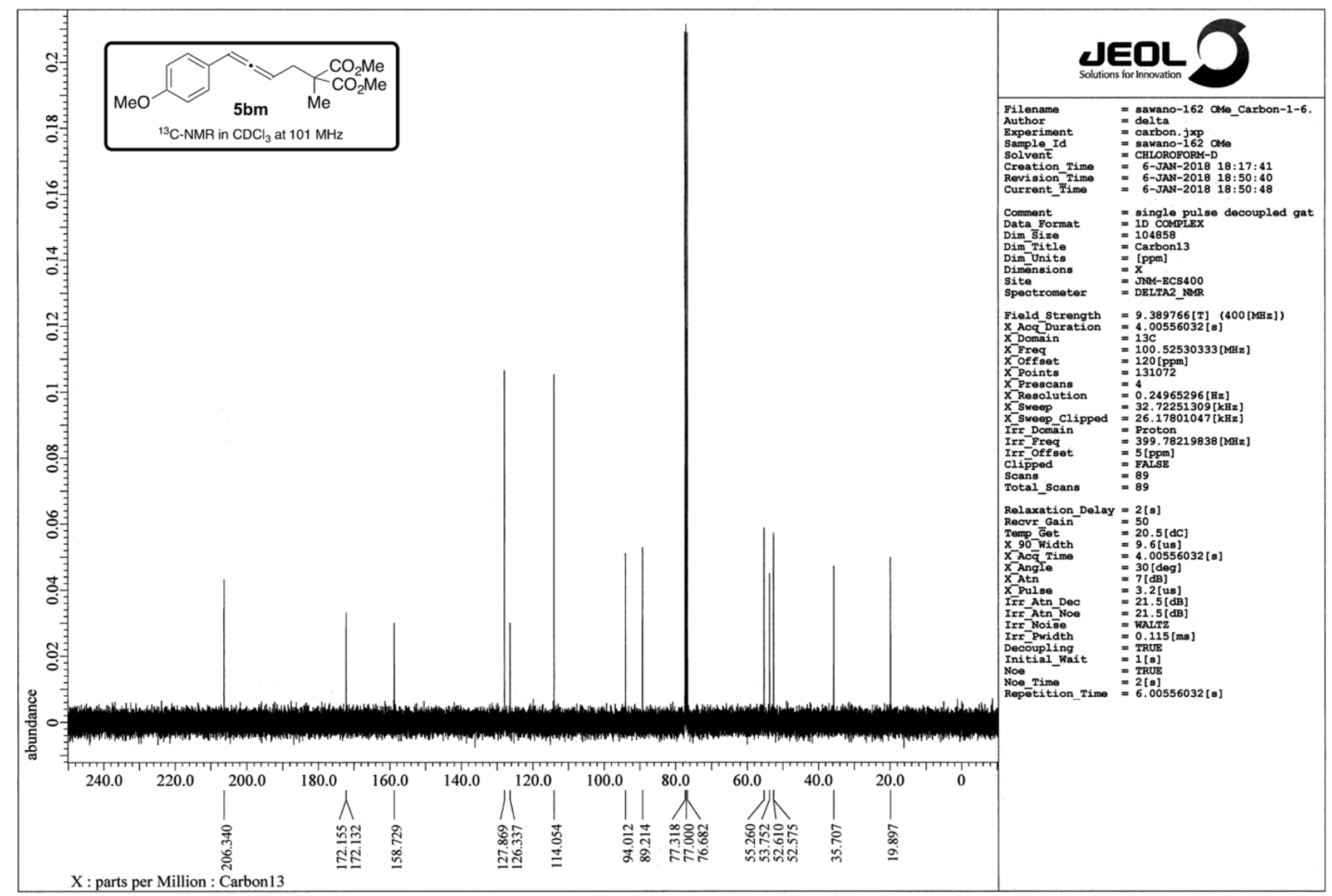

Figure S4. ${ }^{13} \mathrm{C}-\mathrm{NMR}$ Spectrum of $\mathbf{5 b m}$ in $\mathrm{CDCl}_{3}$ at $101 \mathrm{MHz}$. 


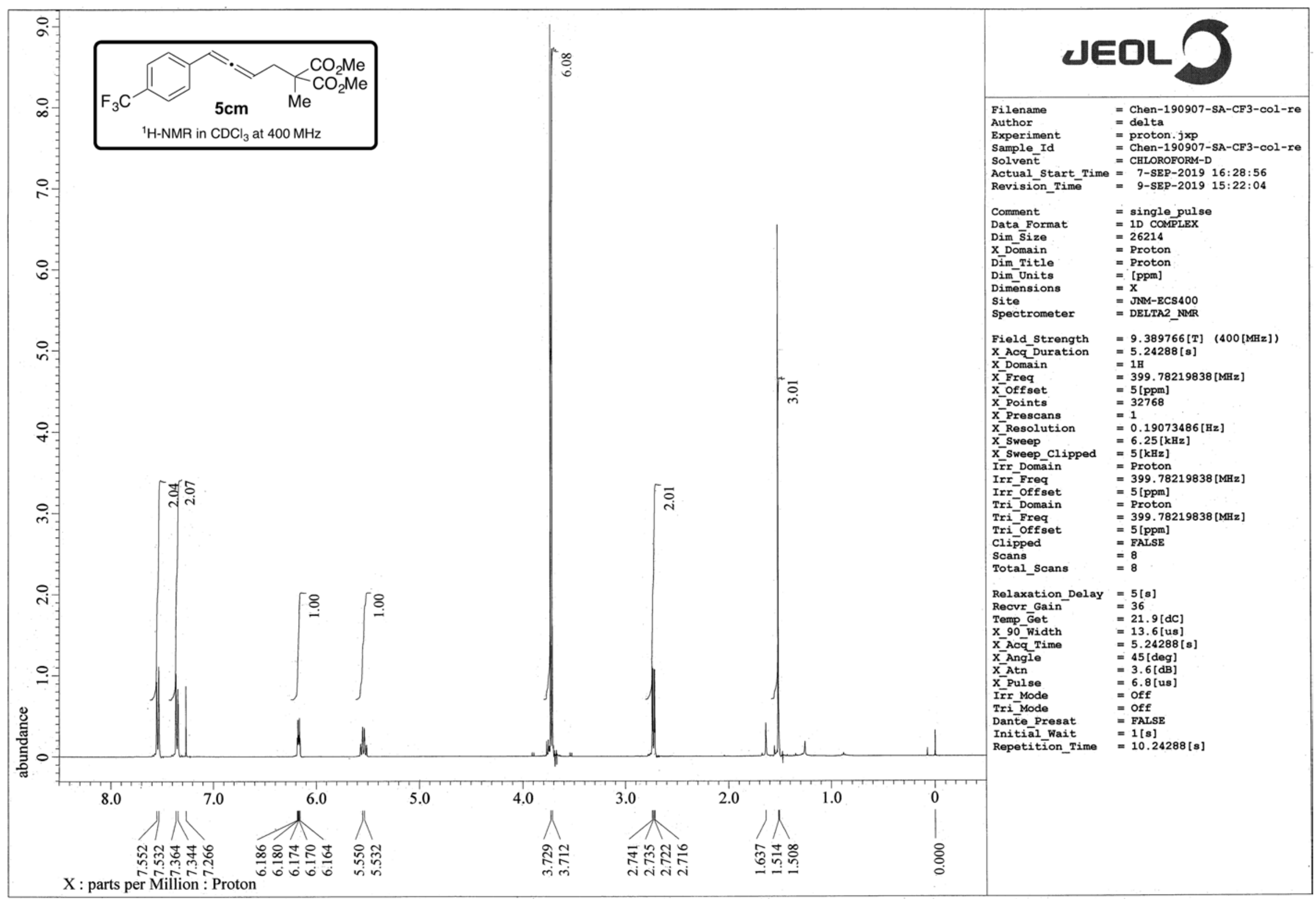

Figure S5. ${ }^{1} \mathrm{H}-\mathrm{NMR}$ Spectrum of $\mathbf{5} \mathbf{c m}$ in $\mathrm{CDCl}_{3}$ at $400 \mathrm{MHz}$. 


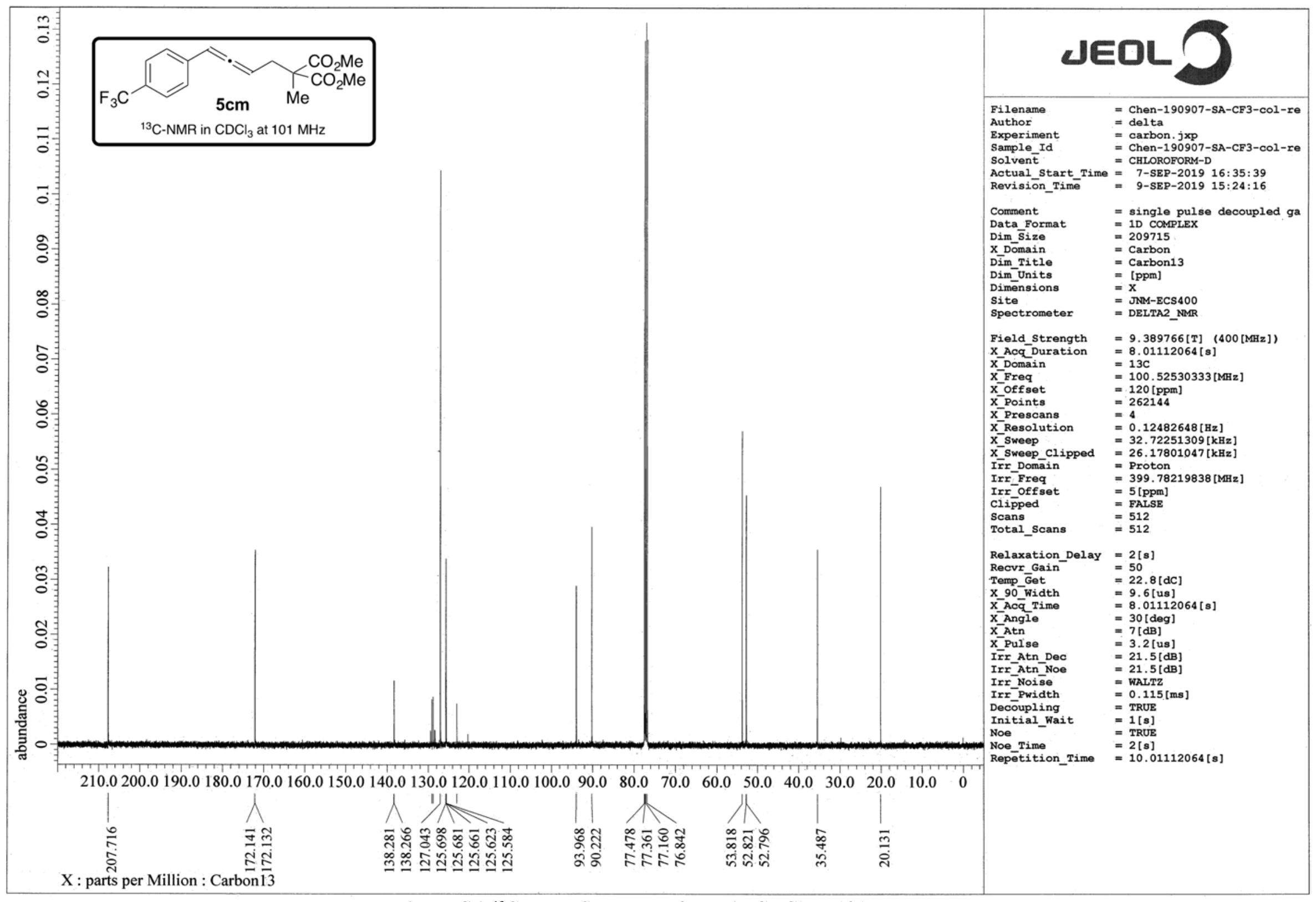

Figure S6. ${ }^{13} \mathrm{C}-\mathrm{NMR}$ Spectrum of $\mathbf{5} \mathbf{c m}$ in $\mathrm{CDCl}_{3}$ at $101 \mathrm{MHz}$. 


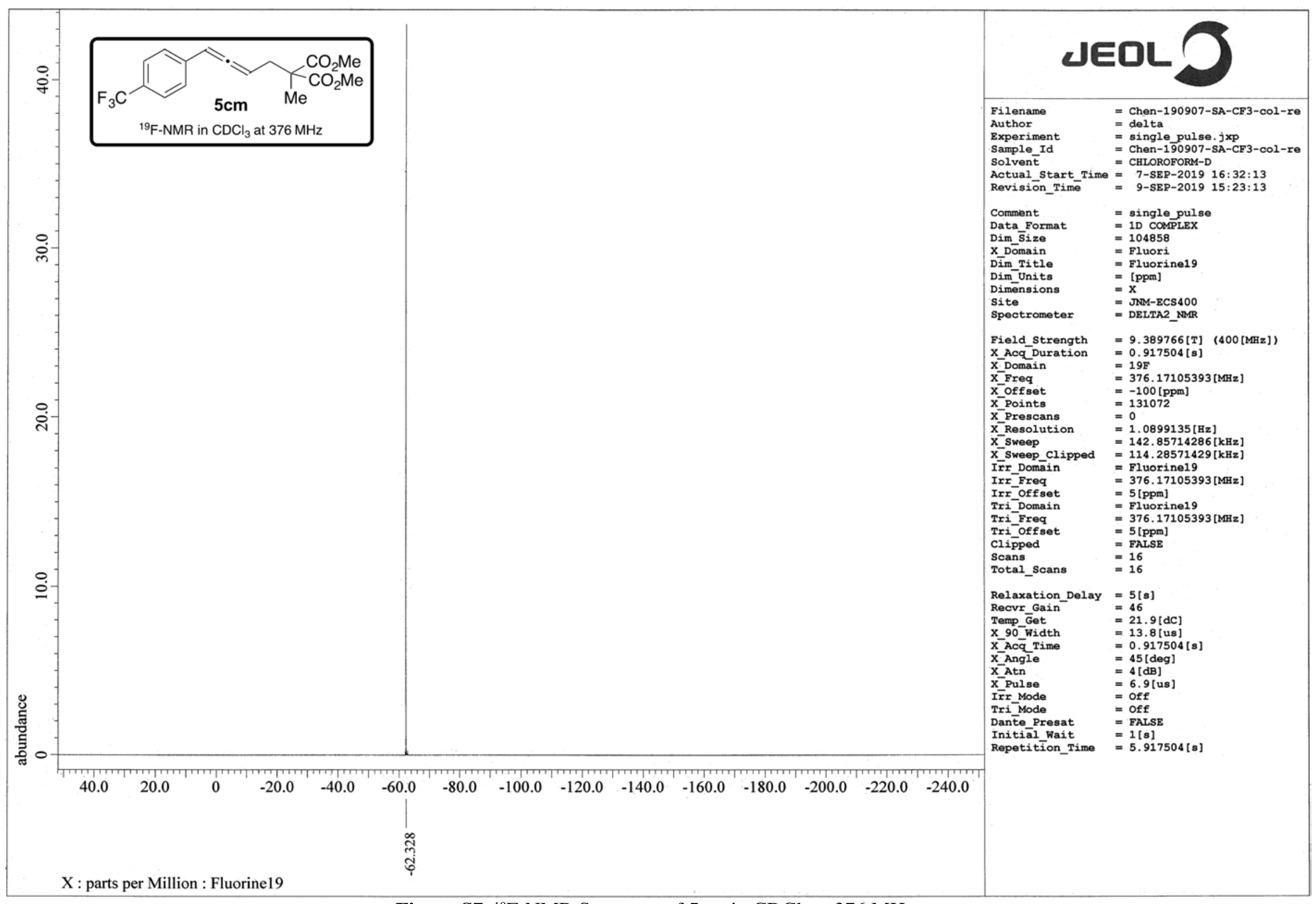

Figure S7. ${ }^{10} \mathrm{~F}-\mathrm{NMR}$ Spectrum of $\mathbf{5 c m}$ in $\mathrm{CDCl}_{3}$ at $376 \mathrm{MHz}$. 


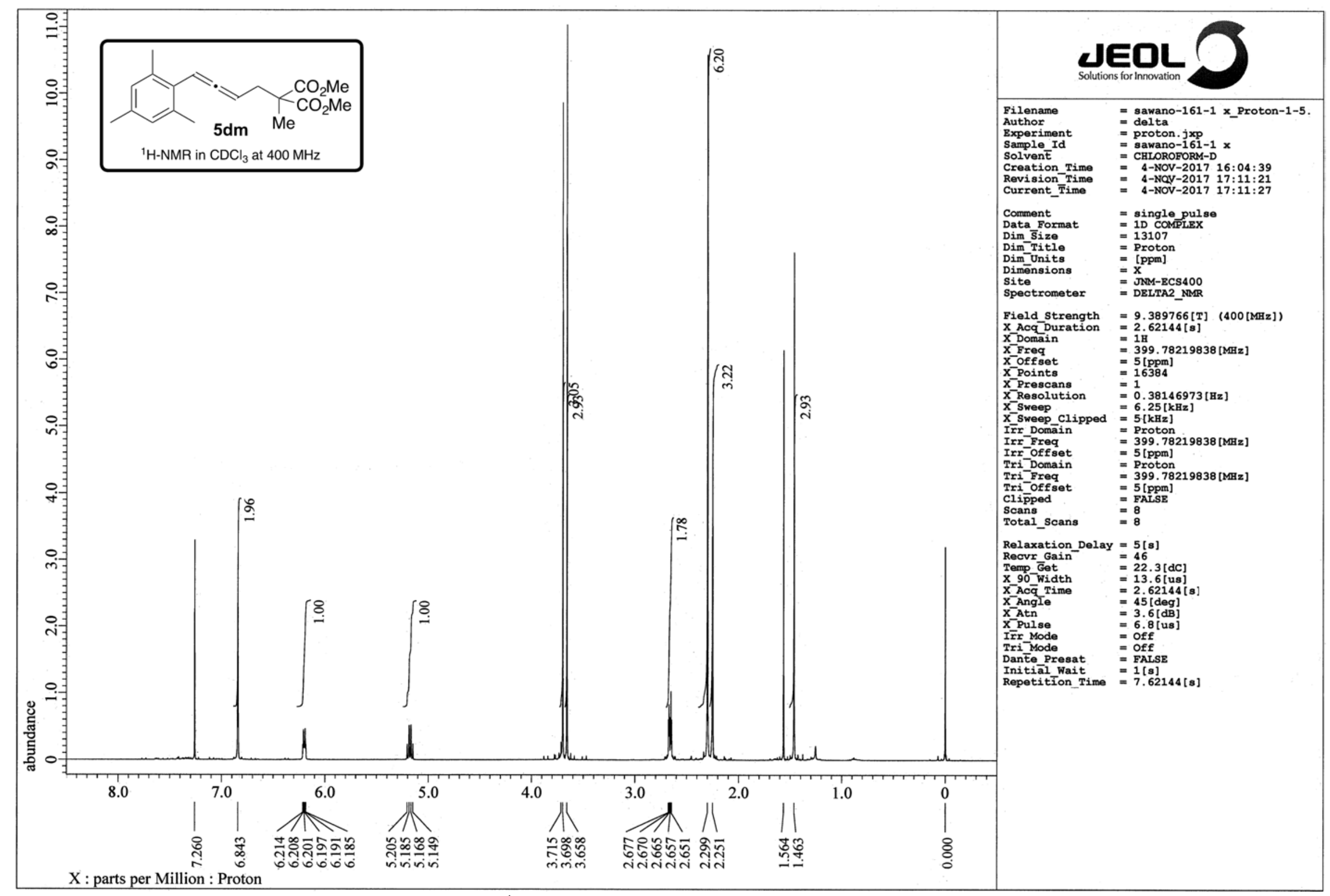

Figure S8. ${ }^{1} \mathrm{H}-\mathrm{NMR}$ Spectrum of $\mathbf{5 d m}$ in $\mathrm{CDCl}_{3}$ at $400 \mathrm{MHz}$. 


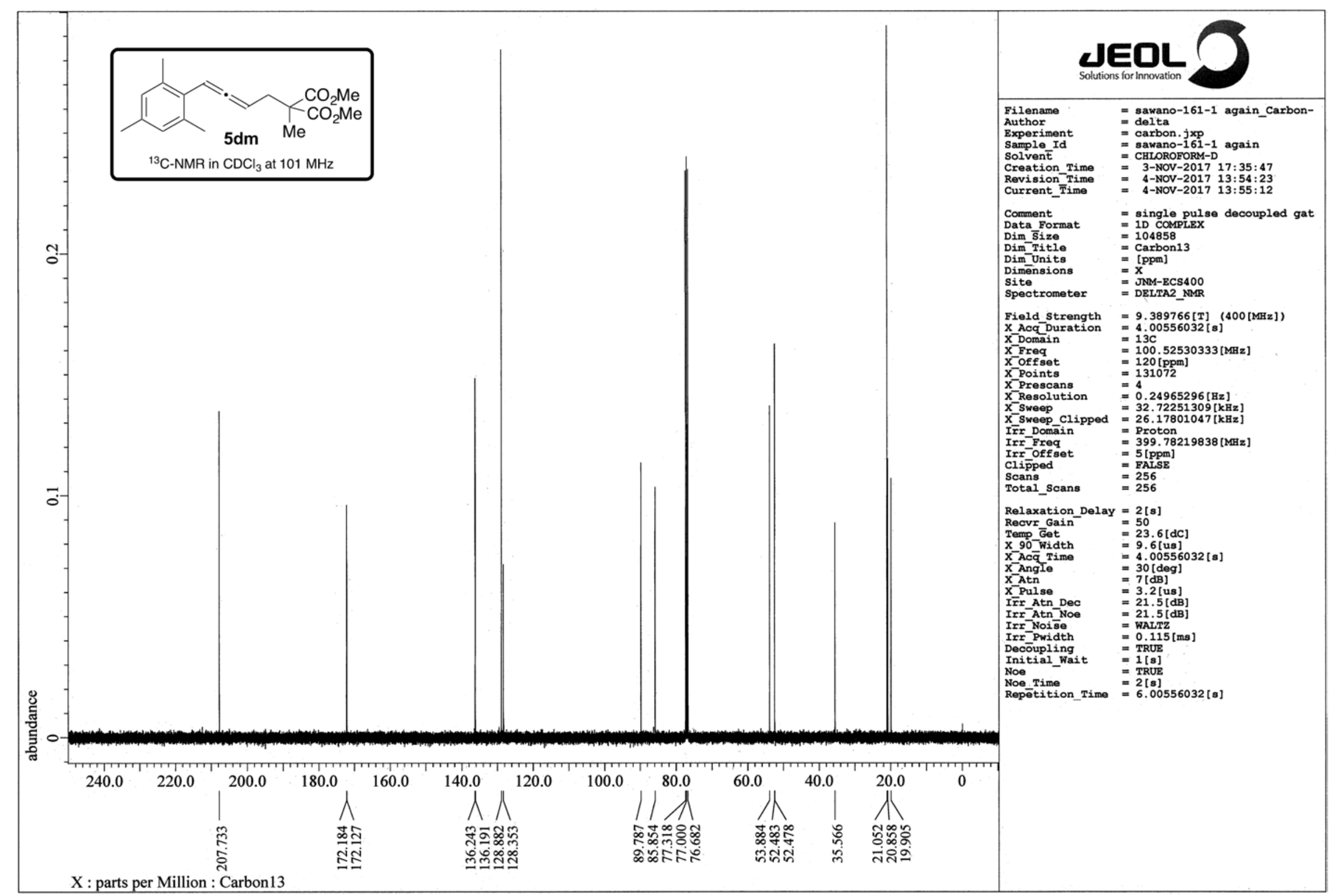

Figure S9. ${ }^{13} \mathrm{C}-\mathrm{NMR}$ Spectrum of $\mathbf{5 d m}$ in $\mathrm{CDCl}_{3}$ at $101 \mathrm{MHz}$. 


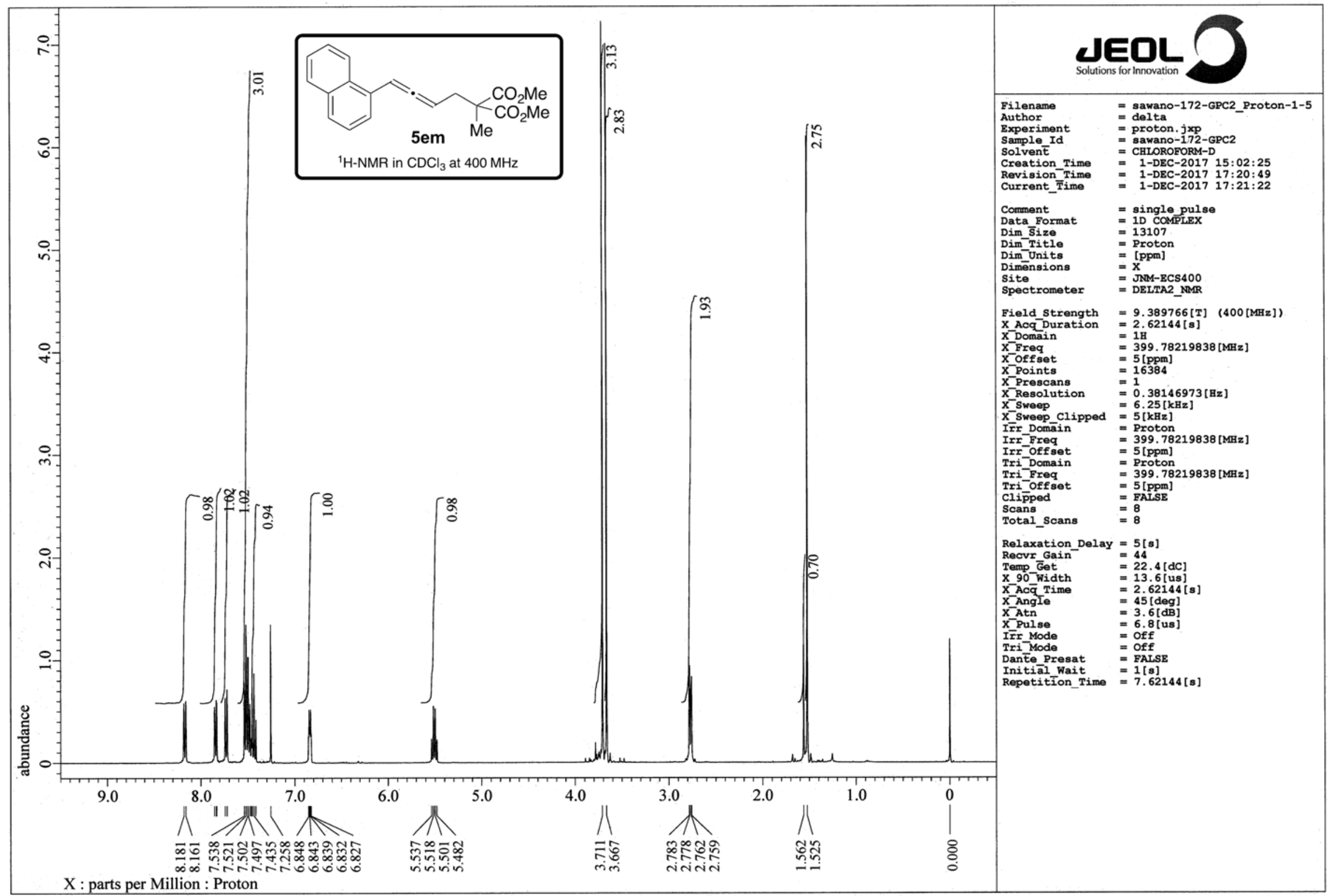

Figure S10. ${ }^{1} \mathrm{H}-\mathrm{NMR}$ Spectrum of $\mathbf{5 e m}$ in $\mathrm{CDCl}_{3}$ at $400 \mathrm{MHz}$. 


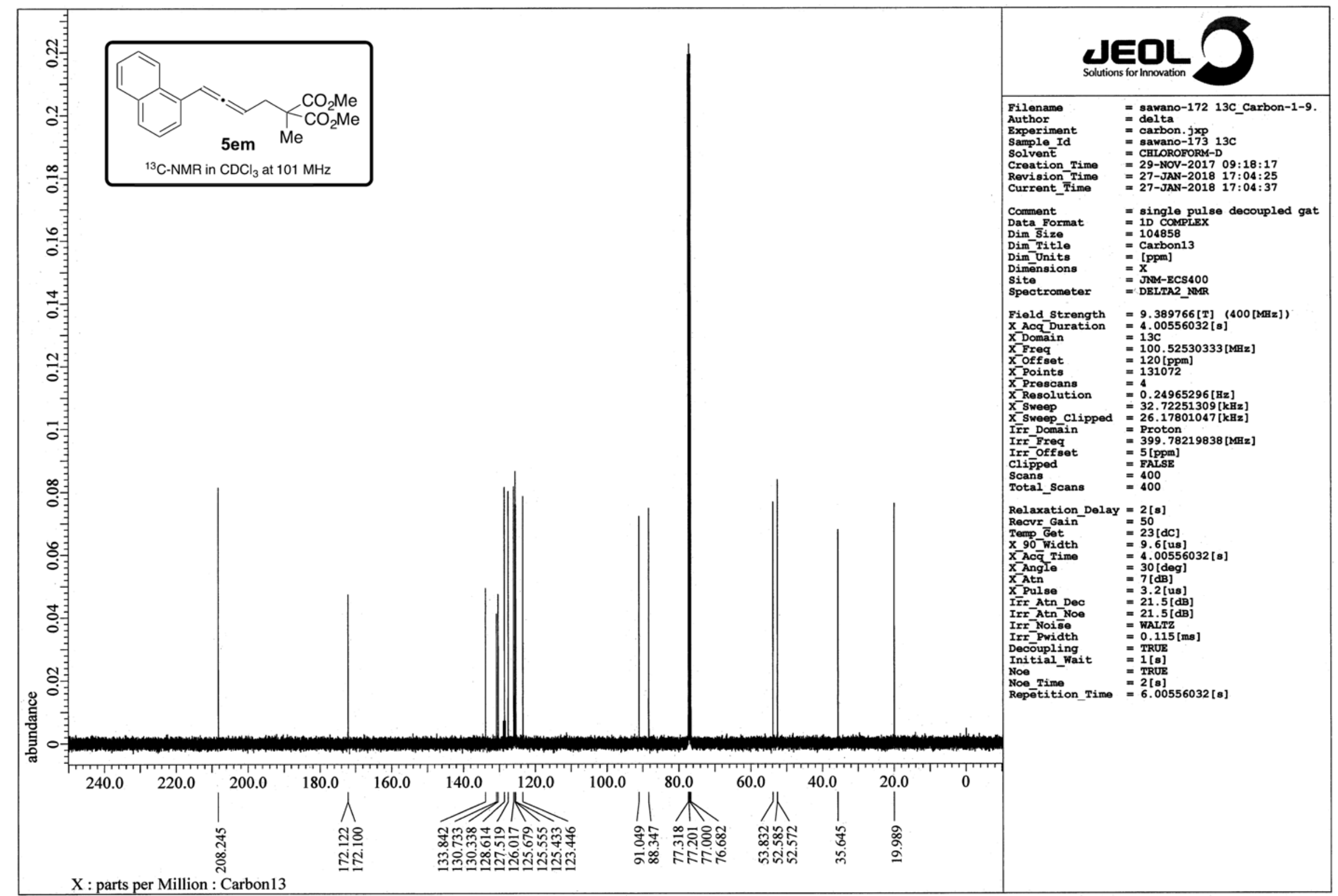

Figure S11. ${ }^{13} \mathrm{C}-\mathrm{NMR}$ Spectrum of $5 \mathbf{e m}$ in $\mathrm{CDCl}_{3}$ at $101 \mathrm{MHz}$. 


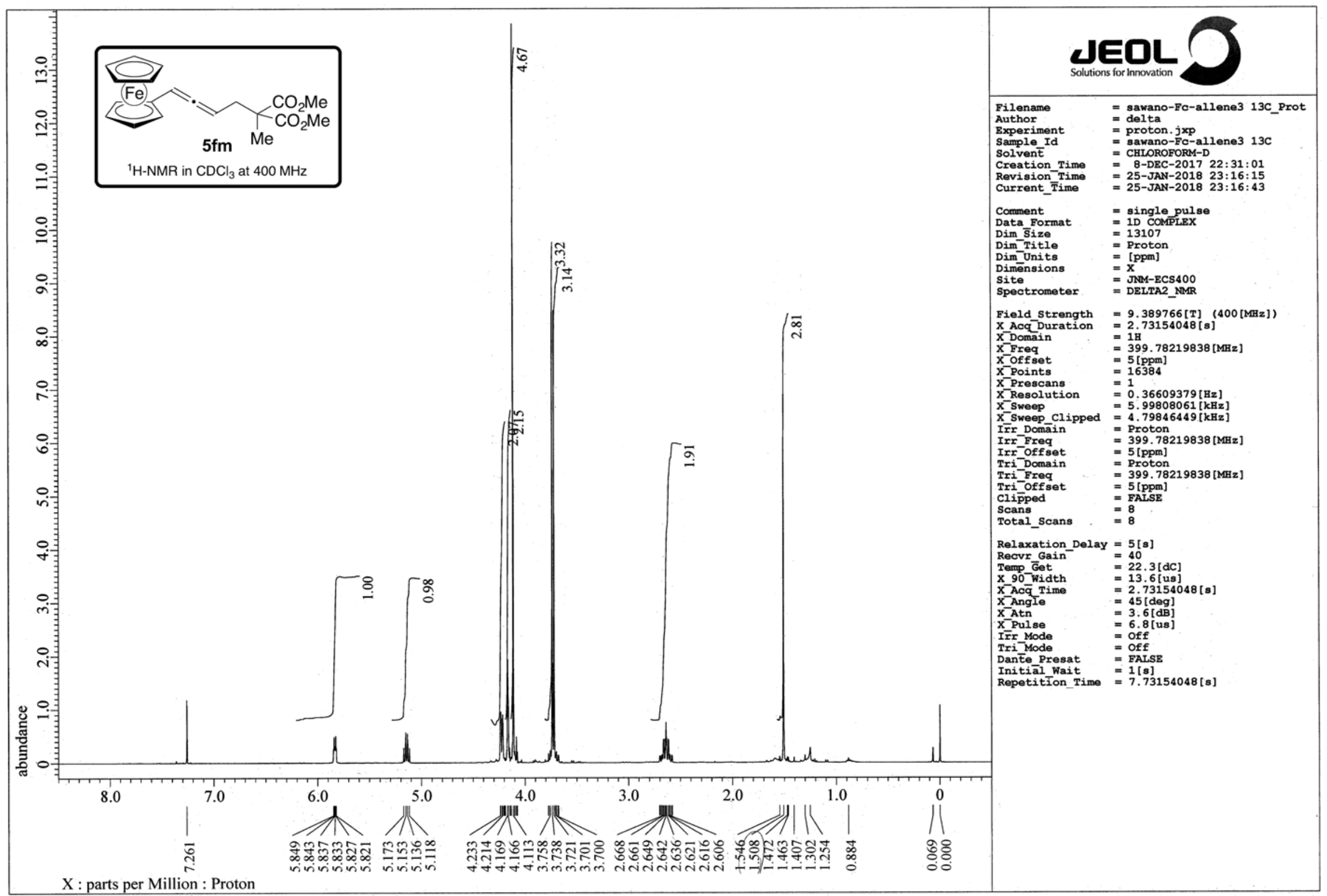

Figure S12. ${ }^{1} \mathrm{H}-\mathrm{NMR}$ Spectrum of $\mathbf{5 f m}$ in $\mathrm{CDCl}_{3}$ at $400 \mathrm{MHz}$. 


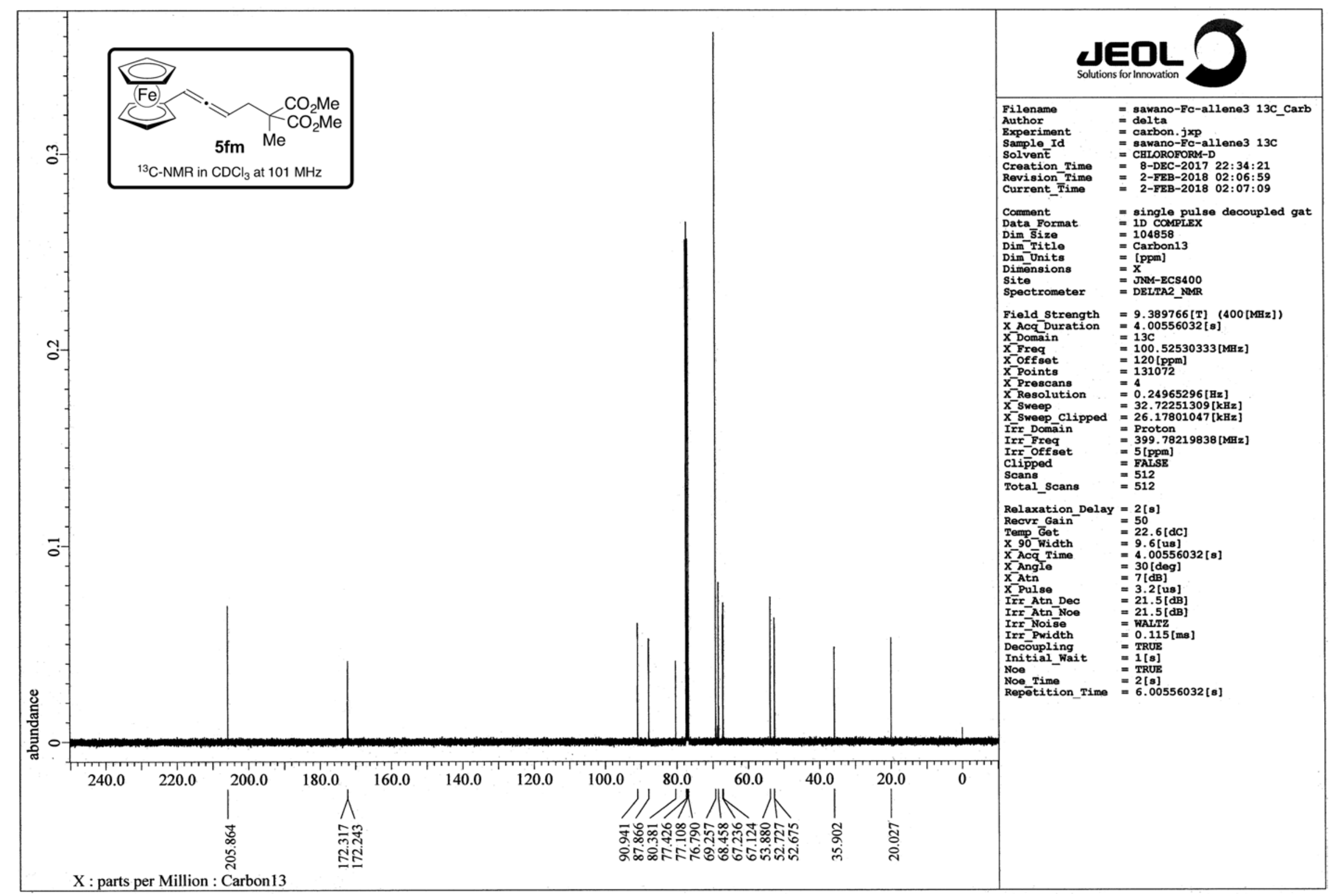

Figure S13. ${ }^{13} \mathrm{C}-\mathrm{NMR}$ Spectrum of $\mathbf{5} \mathbf{f m}$ in $\mathrm{CDCl}_{3}$ at $101 \mathrm{MHz}$. 


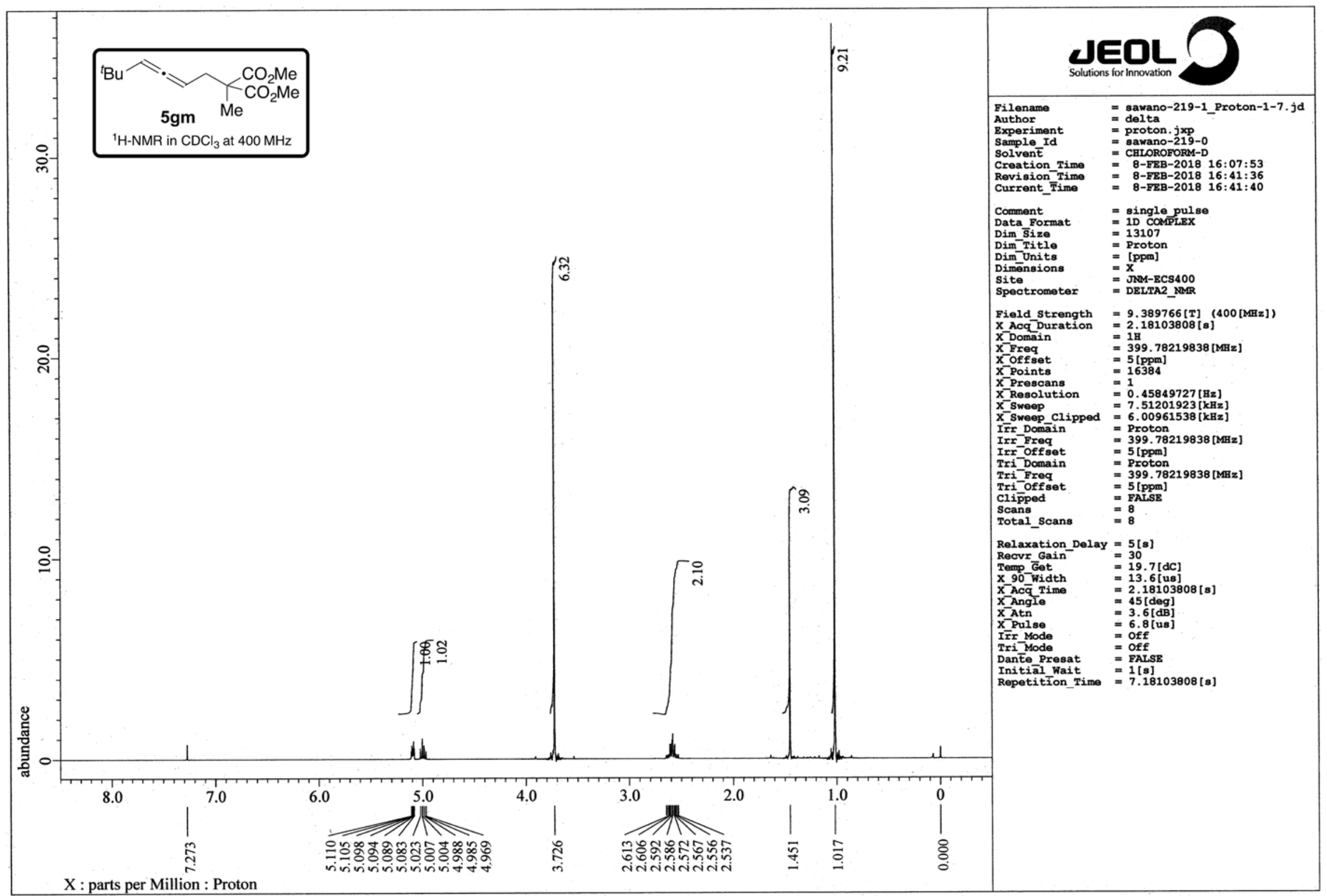

Figure S14. ${ }^{1} \mathrm{H}-\mathrm{NMR}$ Spectrum of $\mathbf{5 g m}$ in $\mathrm{CDCl}_{3}$ at $400 \mathrm{MHz}$. 


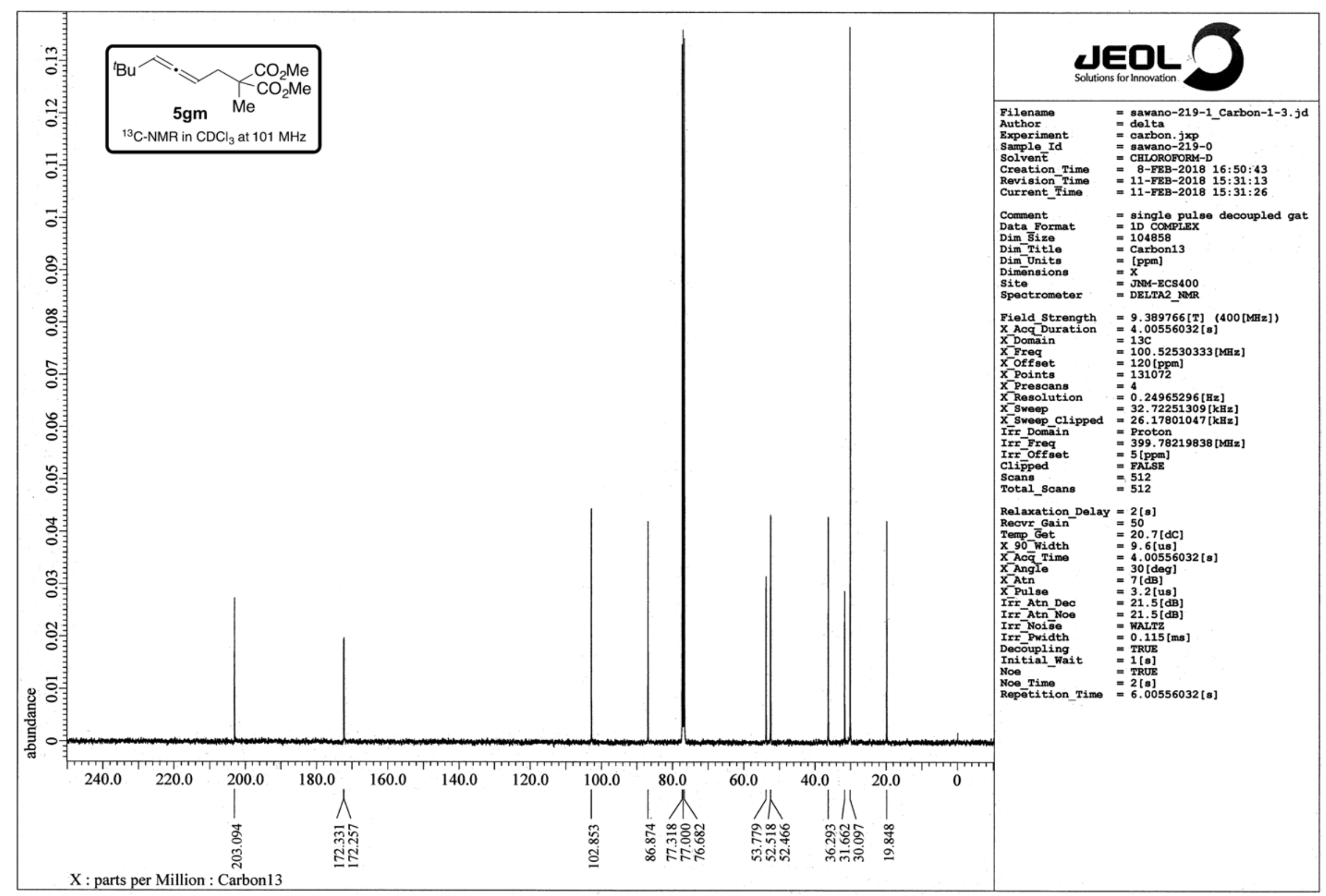

Figure S15. ${ }^{13} \mathrm{C}-\mathrm{NMR}$ Spectrum of $\mathbf{5 g m}$ in $\mathrm{CDCl}_{3}$ at $101 \mathrm{MHz}$. 


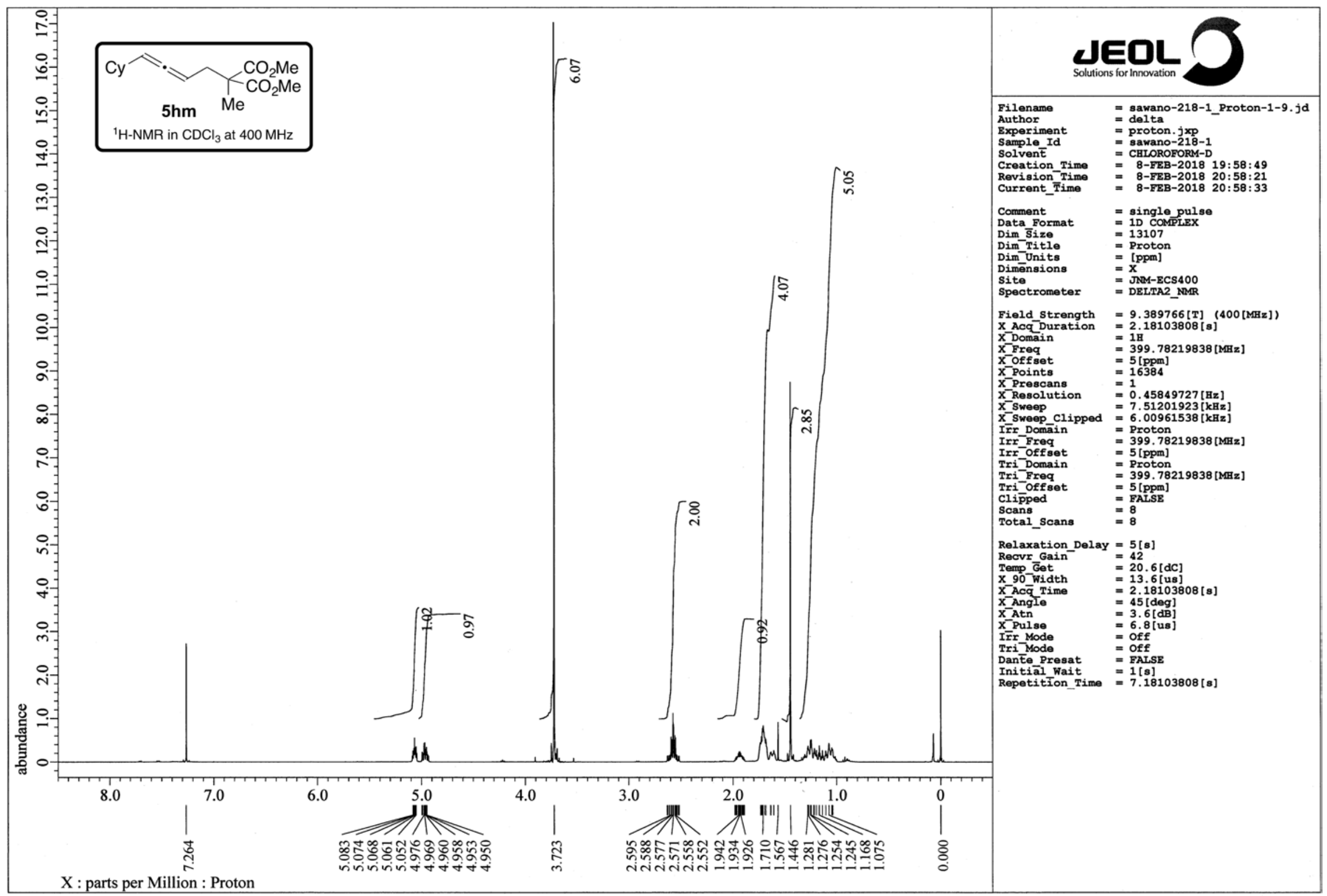

Figure S16. ${ }^{1} \mathrm{H}-\mathrm{NMR}$ Spectrum of $\mathbf{5} \mathbf{h m}$ in $\mathrm{CDCl}_{3}$ at $400 \mathrm{MHz}$. 


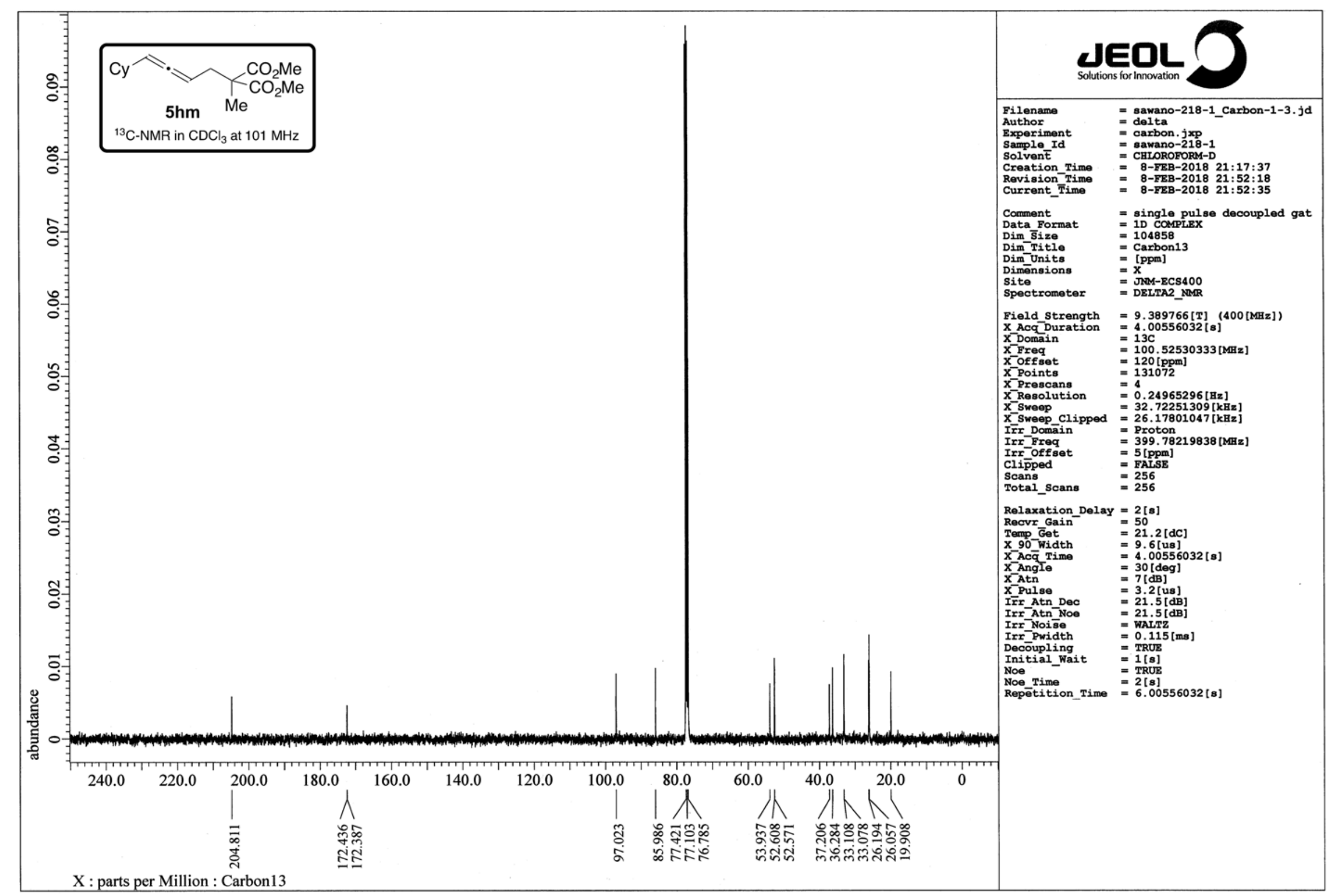

Figure S17. ${ }^{13} \mathrm{C}-\mathrm{NMR}$ Spectrum of $\mathbf{5} \mathbf{h m}$ in $\mathrm{CDCl}_{3}$ at $101 \mathrm{MHz}$. 


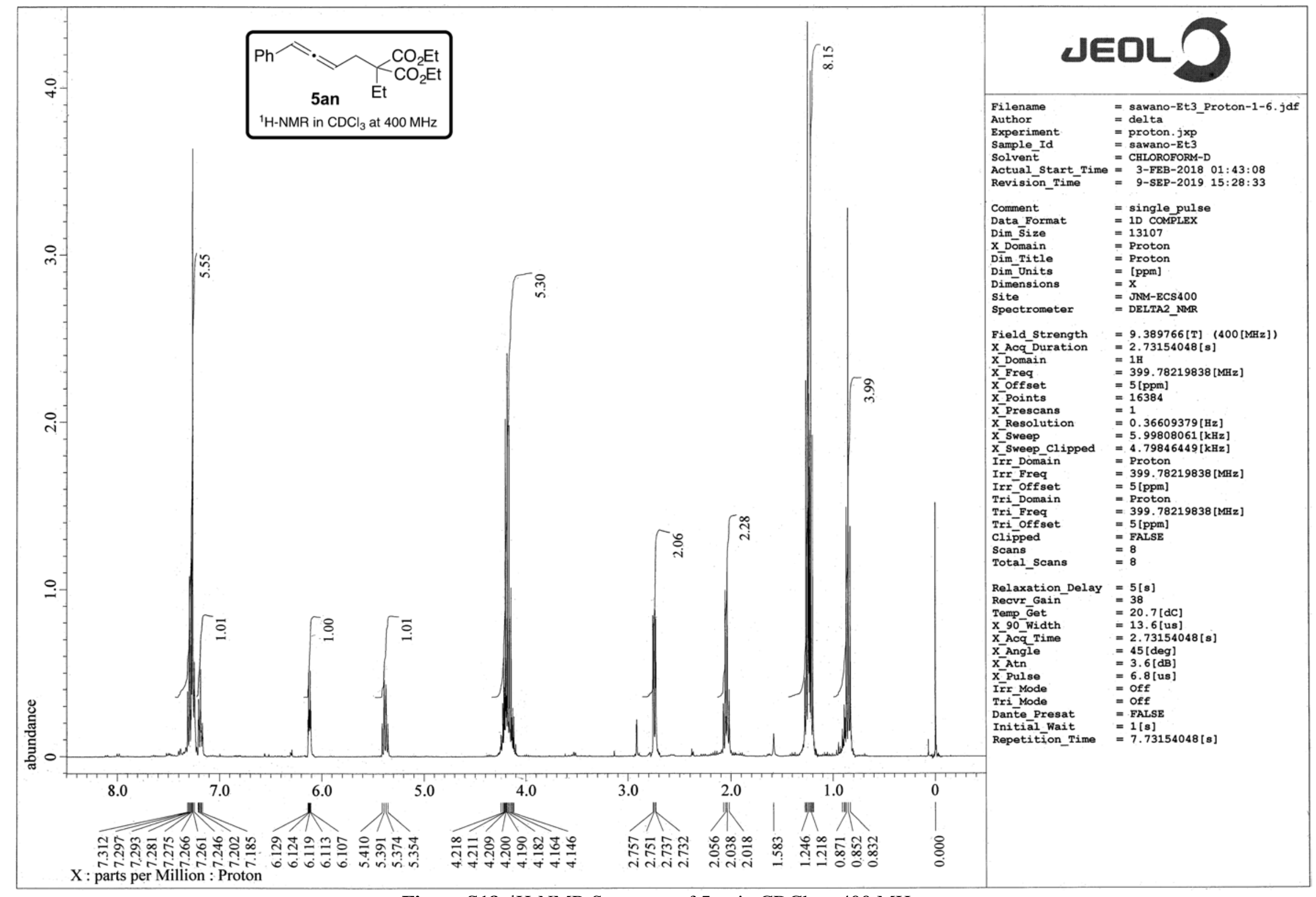

Figure S18. ${ }^{1} \mathrm{H}-\mathrm{NMR}$ Spectrum of $\mathbf{5 a n}$ in $\mathrm{CDCl}_{3}$ at $400 \mathrm{MHz}$. 


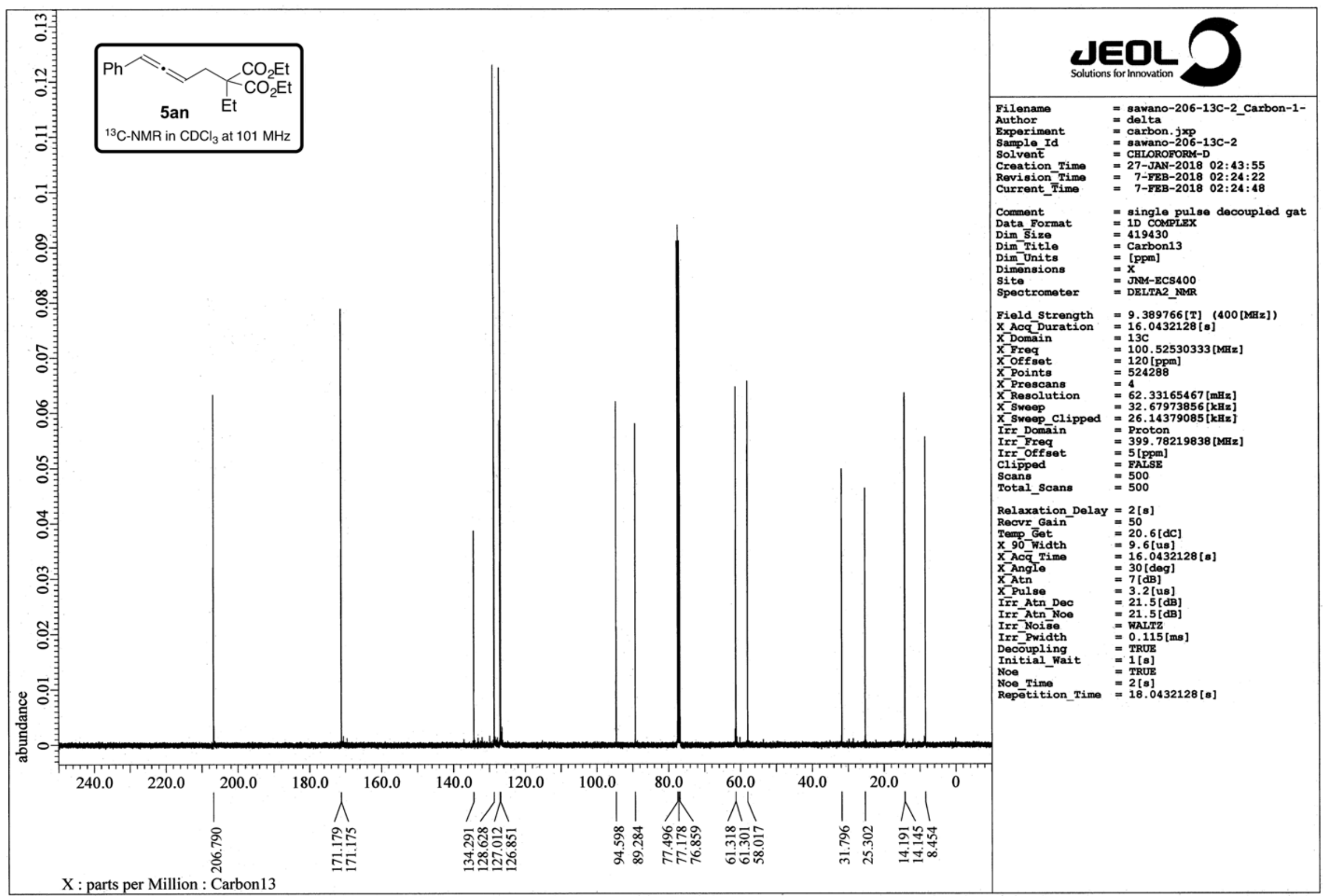

Figure S19. ${ }^{13} \mathrm{C}-\mathrm{NMR}$ Spectrum of $5 \mathrm{an}$ in $\mathrm{CDCl}_{3}$ at $101 \mathrm{MHz}$. 


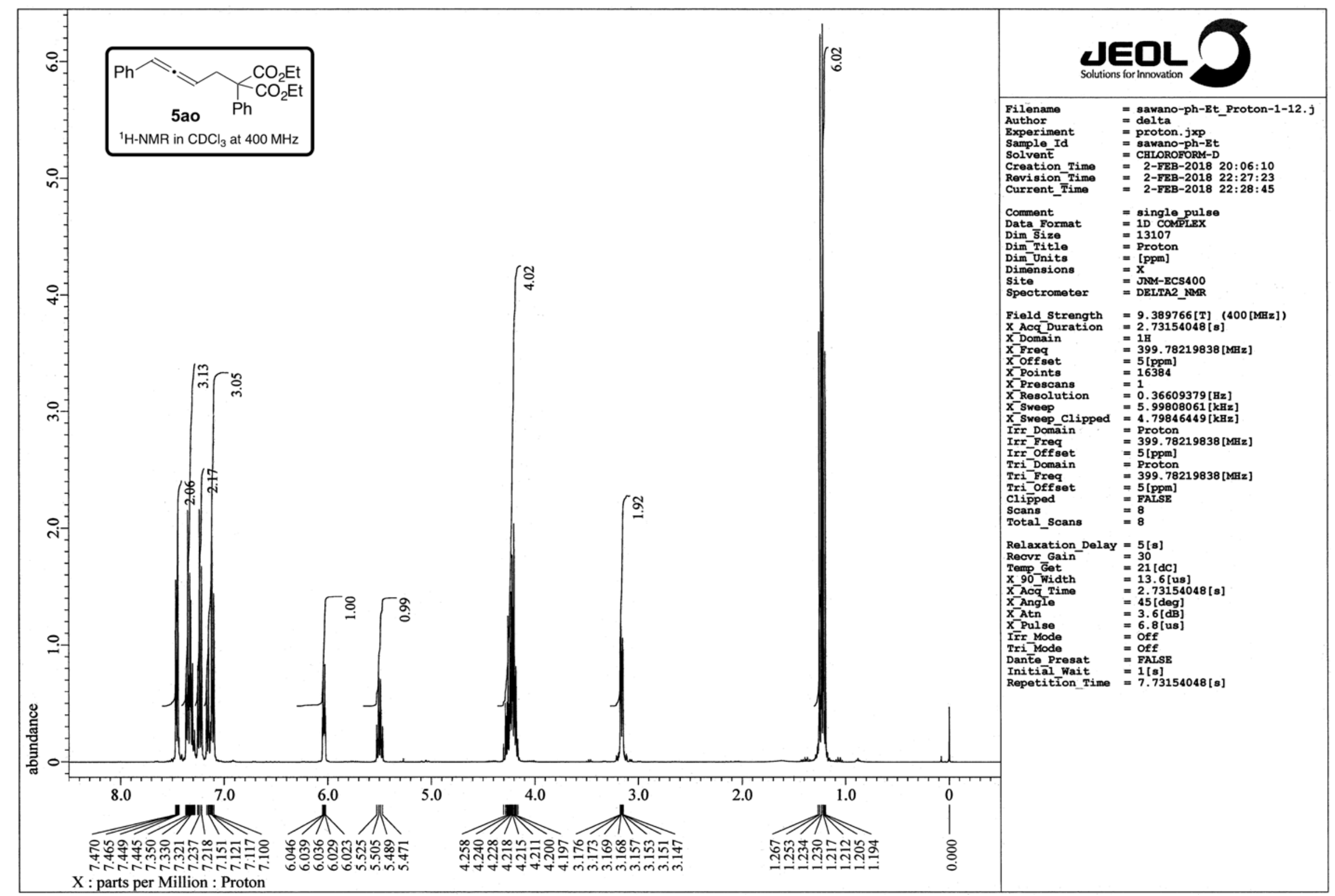

Figure S20. ${ }^{1} \mathrm{H}-\mathrm{NMR}$ Spectrum of $\mathbf{5 a o}$ in $\mathrm{CDCl}_{3}$ at $400 \mathrm{MHz}$. 


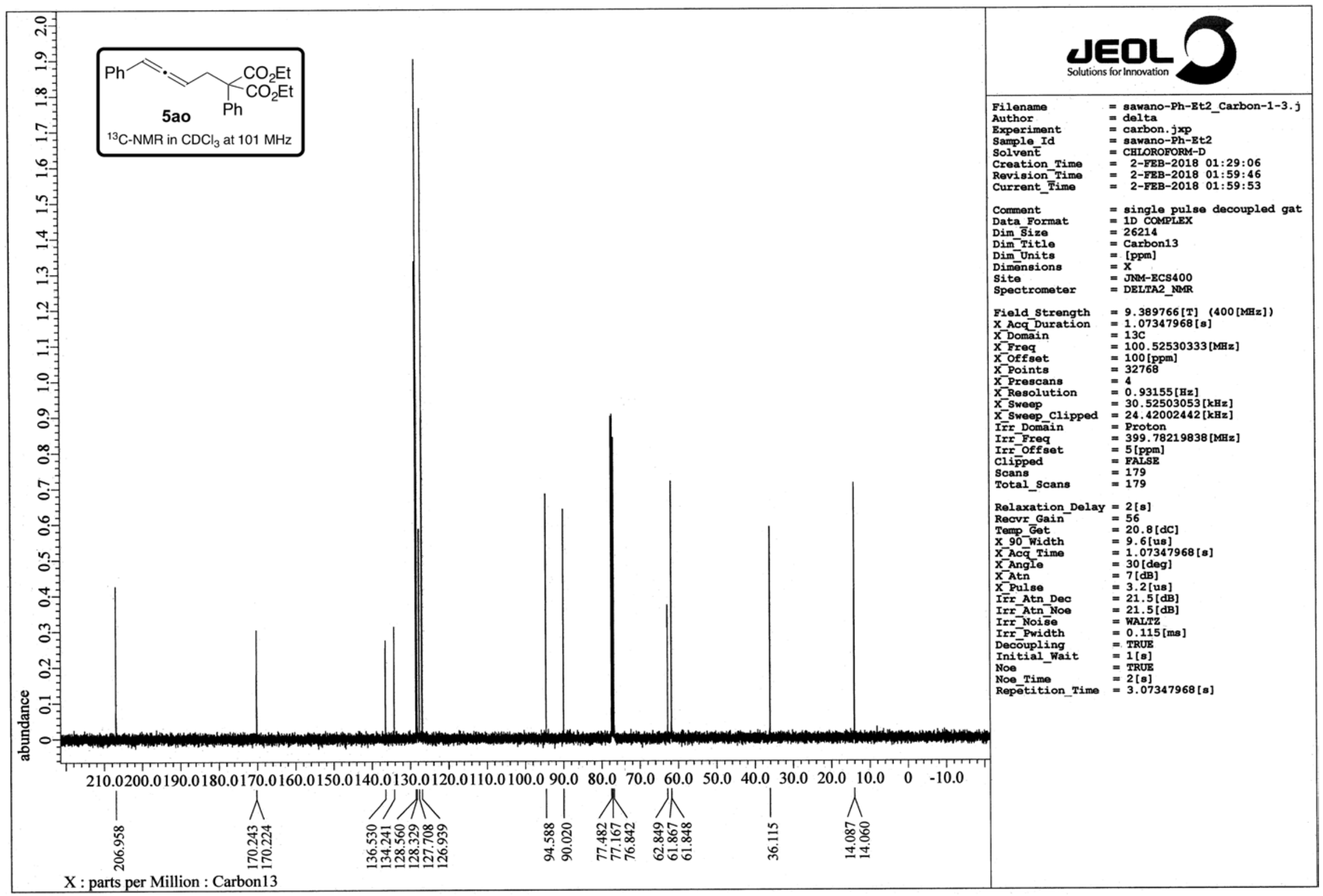

Figure S21. ${ }^{13} \mathrm{C}-\mathrm{NMR}$ Spectrum of $\mathbf{5 a o}$ in $\mathrm{CDCl}_{3}$ at $101 \mathrm{MHz}$. 


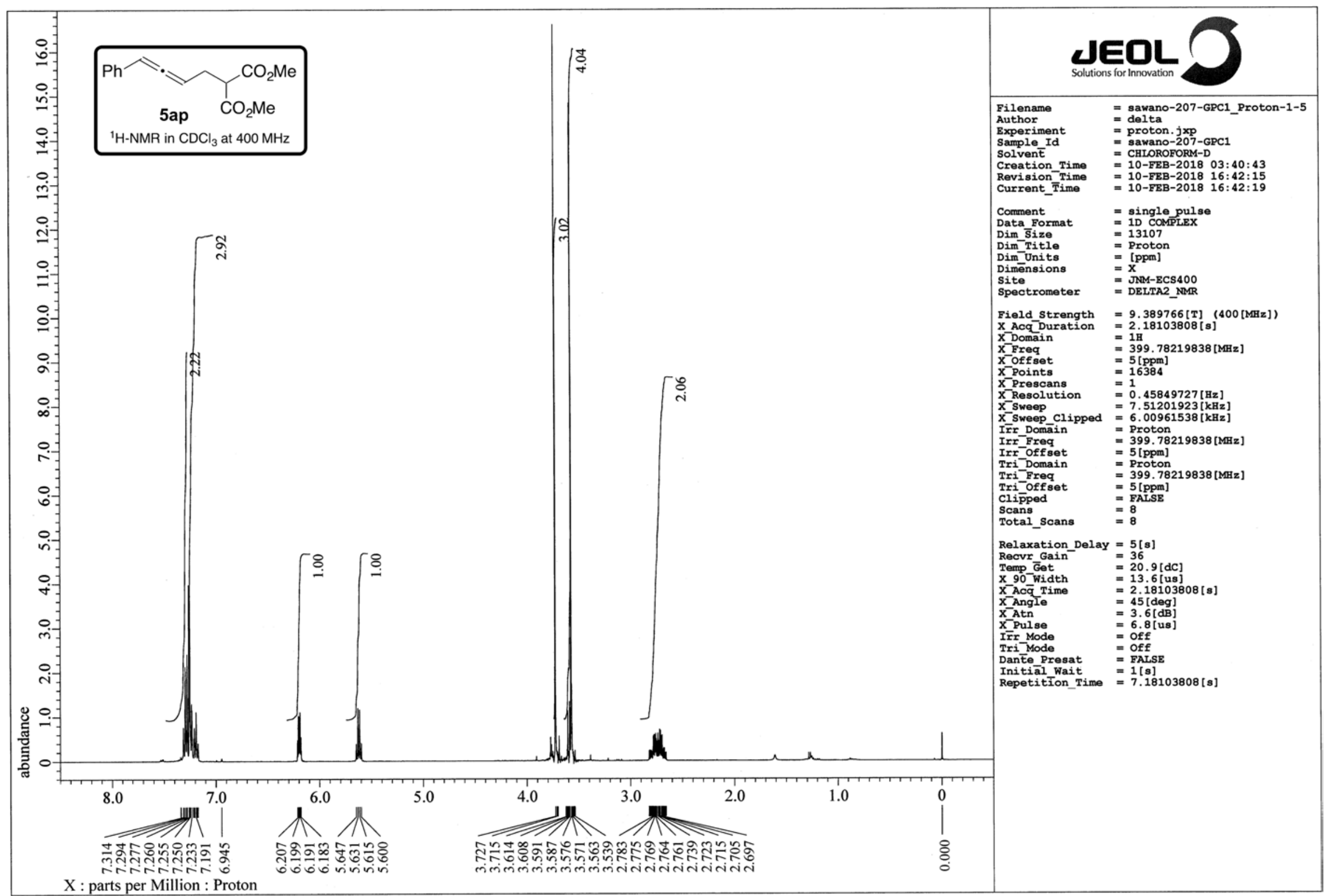

Figure S22. ${ }^{1} \mathrm{H}-\mathrm{NMR}$ Spectrum of 5 ap in $\mathrm{CDCl}_{3}$ at $400 \mathrm{MHz}$. 


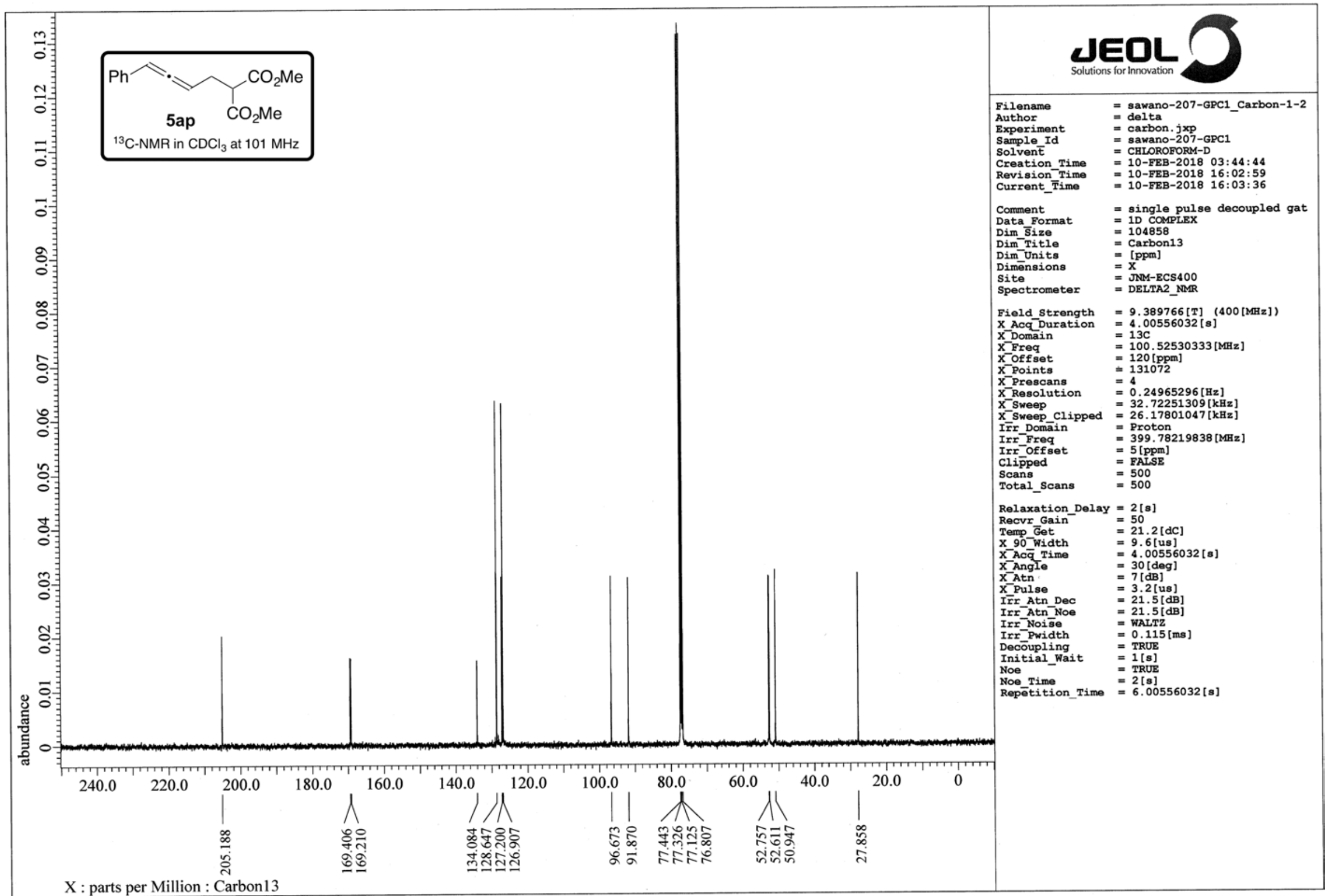

Figure S23. ${ }^{13} \mathrm{C}-\mathrm{NMR}$ Spectrum of $\mathbf{5 a p}$ in $\mathrm{CDCl}_{3}$ at $101 \mathrm{MHz}$. 


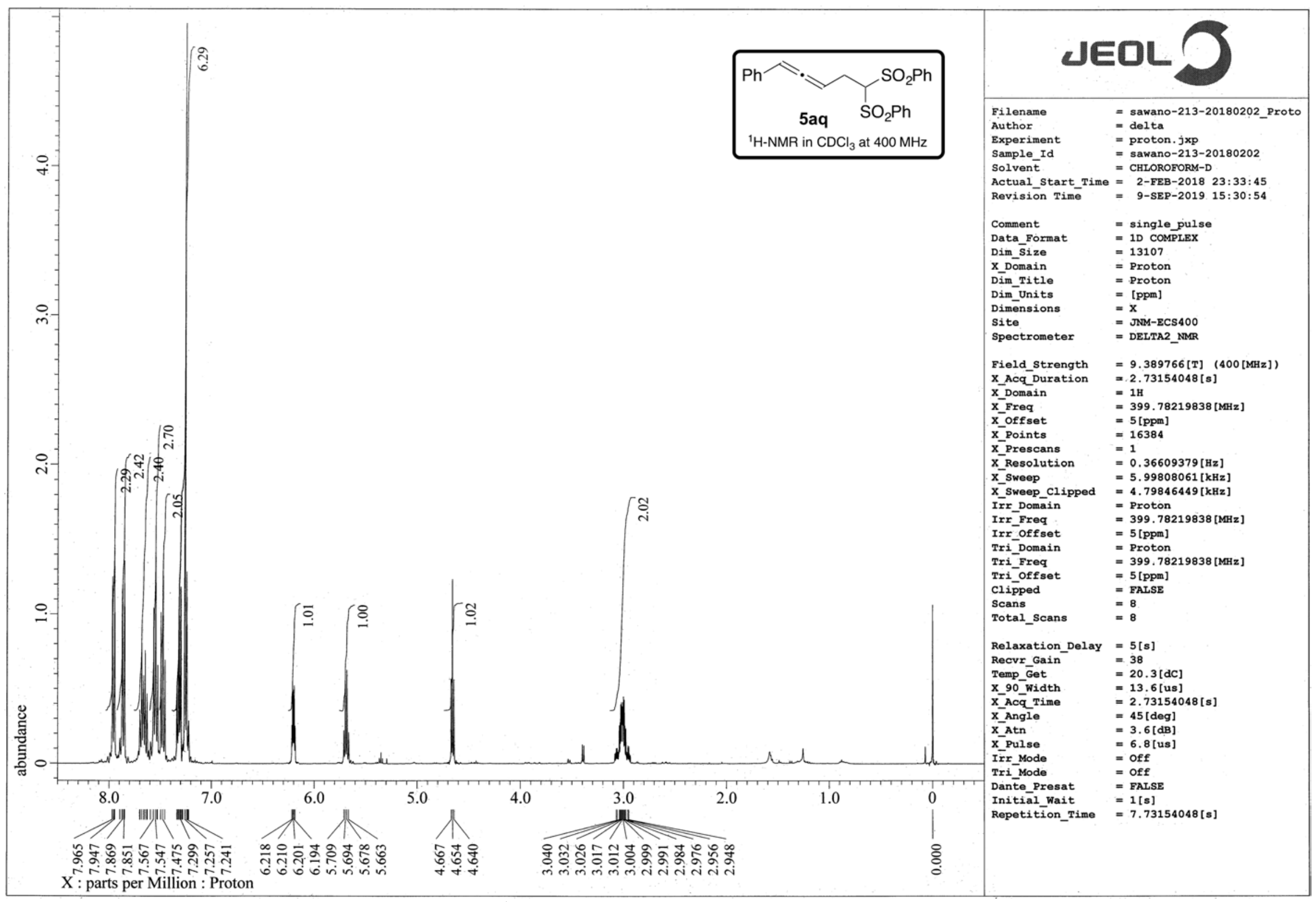

Figure S24. ${ }^{1} \mathrm{H}-\mathrm{NMR}$ Spectrum of $\mathbf{5 a q}$ in $\mathrm{CDCl}_{3}$ at $400 \mathrm{MHz}$. 


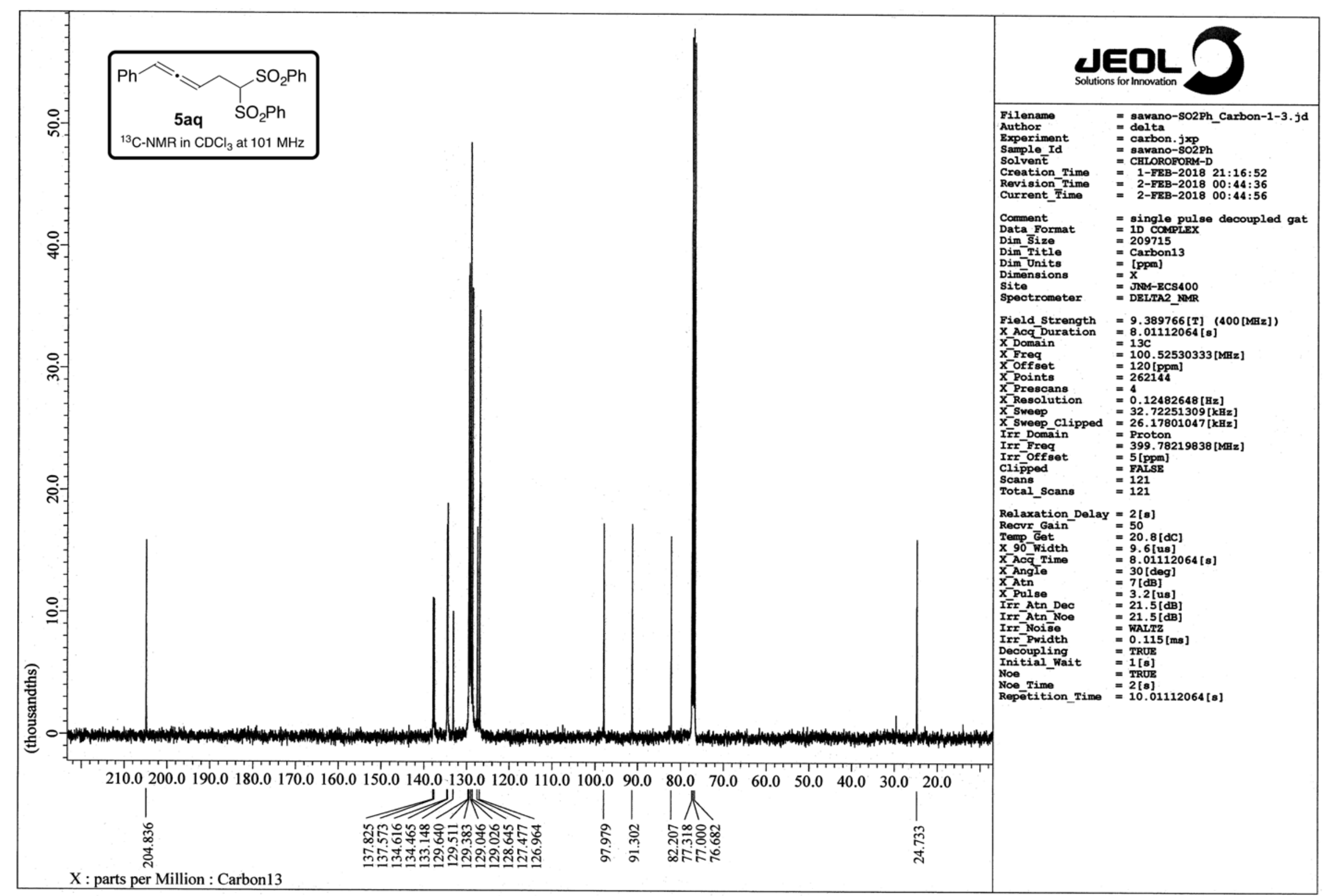

Figure S25. ${ }^{13} \mathrm{C}-\mathrm{NMR}$ Spectrum of $\mathbf{5 a q}$ in $\mathrm{CDCl}_{3}$ at $101 \mathrm{MHz}$. 


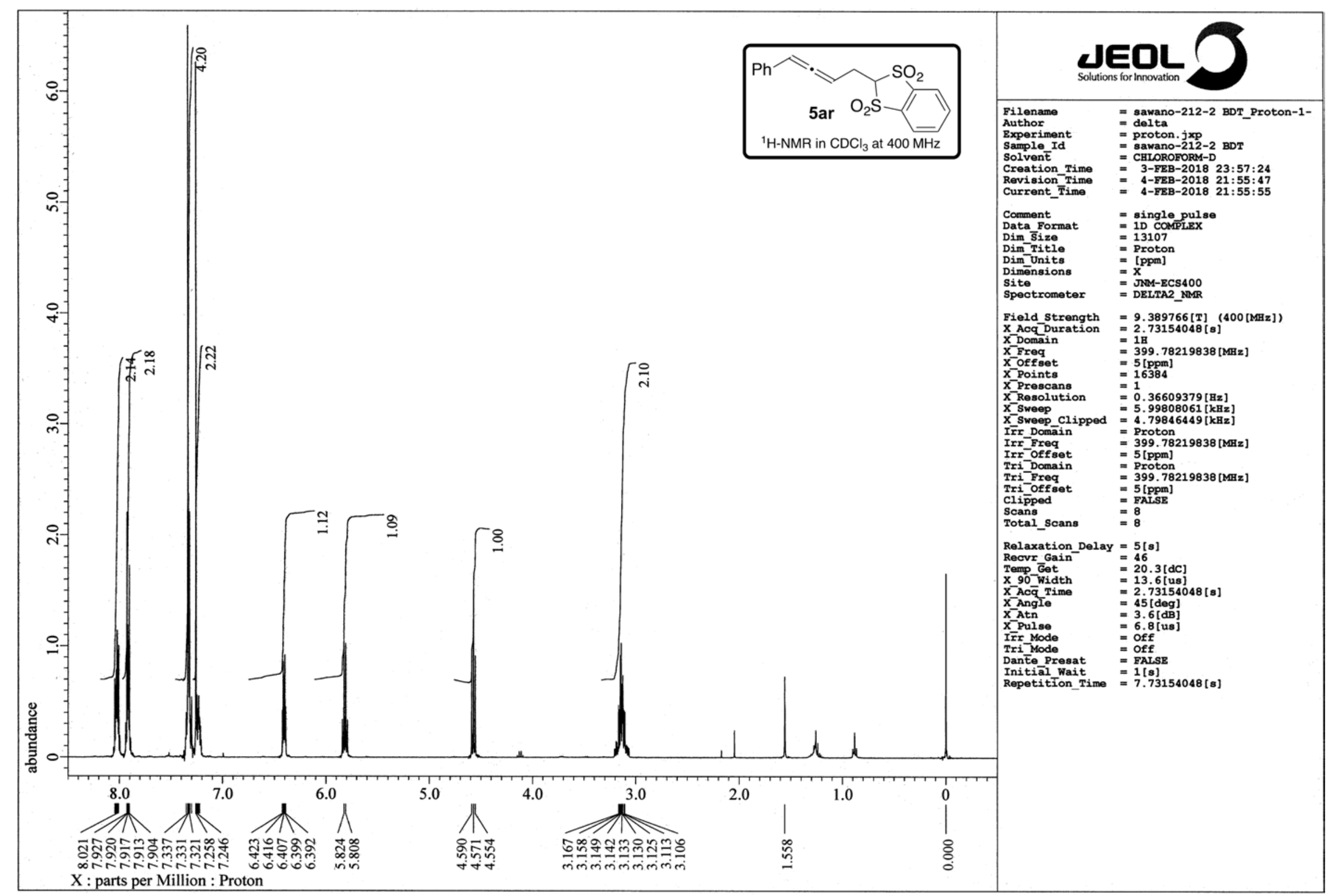

Figure S26. ${ }^{1} \mathrm{H}-\mathrm{NMR}$ Spectrum of 5 ar in $\mathrm{CDCl}_{3}$ at $400 \mathrm{MHz}$. 


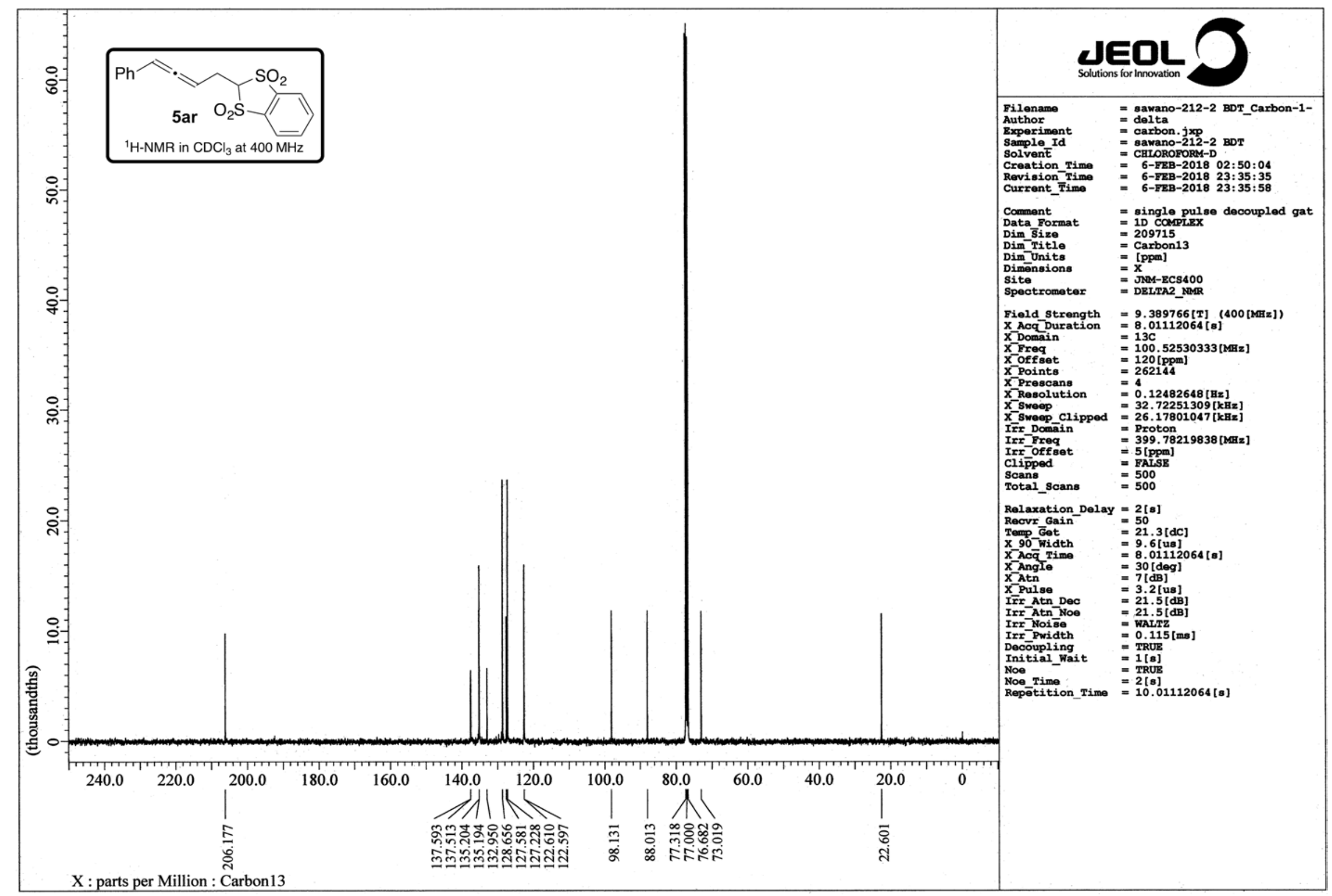

Figure S27. ${ }^{13} \mathrm{C}-\mathrm{NMR}$ Spectrum of 5 ar in $\mathrm{CDCl}_{3}$ at $101 \mathrm{MHz}$. 